\title{
Attenuation of the intermittent punishment effect: The effect of interpolated punishment and nonreward trials
}

\author{
R. K. BANKS \\ University of Waterloo, Waterloo, Ontario, Canada N2L 361
}

\begin{abstract}
Intermittent punishment of a response is known to increase the persistence of that response to more intense and/or more frequent punishment. In the present experiment, rats with a history of intermittent punishment were subjected to blocks of trials on which every response was both punished and nonreinforced. In a subsequent test for persistence to a high level of punishment, these animals failed to show greater persistence than controls. The results were seen as evidence for the role of an association between fear and the intermittently punished response and were interpreted as consistent with a conditioning model interpretation of the effect of intermittent punishment training.
\end{abstract}

If occasional mild punishment is administered during the acquisition of a response, that response acquires a relative immunity to the effects of more frequent or more intense punishment (e.g., Banks, 1966; Miller, 1960). One interpretation of this effect is derived from an extension of Amsel's (1958, 1962) conditioning explanation of the partial reinforcement effect. In these terms, it is argued that during training with intermittent punishment (IP) fear is elicited but, since punishment is relatively mild and infrequent, the conflict between approach and avoidance of the goal is resolved in favor of approach. As training continues, the anımal responds in the presence of fear, receives reinforcement for doing so, and thus forms an association between fear and the punished response. When fear is elicited during more intense or more frequent punishment, there is, therefore, some tendency for IP animals to continue to respond. For animals with no prior history of intermittent punishment, however, strong avoidance tendencies are produced and responding is suppressed. As a result, animals trained under IP show greater persistence than controls. an effect te:med the intermittent punishment effect (IPE).

It follows from this explanation that the IPE should be reduced when intermittent punishment training is followed by any procedure which reduces the ability of fear to elicit approach tendencies. The normal procedure for extinguishing the ability of a stimulus to elicit an instrumental response is to allow that response to occur in the presence of the stimulus and to withhold reinforcement. Thus, the ability of fear to elicit the instrumental response should be reduced if conditions provide for the nonreinforced occurrence of that response in the presence of fear. In the present experiment, this was attempted by interpolating (between IP training and subsequent testing for the IPE) blocks of trials in which every response was followed by both

This work was supported by a grant from The National Research Council of Canada. The author is grateful to Miss L. Krzystofowicz for assistance in data collection. mild punishment and nonreward (punishment was administered at this time to ensure the presence of fear during nonreinforced responding and was kept at a mild level to permit a substantial amount of responding to occur). Subsequent testing for the IPE occurred with high-intensity punishment administered with reward on every trial.

The experiment employed five groups with two treatment phases; its design is summarized in Table 1. A normal intermittent punishment group (IP) receiving IP training in Phase 1, but only continuous reinforcement (CRF) throughout Phase 2, was included to assess the presence of the IPE. A nonintemittently punished control group (NIP) which did not receive punishment training in either Phase 1 or Phase 2 provided a baseline for assessing persistence of the various IP groups. The IP group of primary interest received the same Phase 1 treatment as the normal IP group but, in Phase 2. experienced sessions of contınuous punishment and nonreward trials $(\mathrm{PN})$ interpolated between IP training and testıng. This group is termed an IP.PN group. A third IP group (PN-IP), included to provide a control for the experience of sessions of continuous punishment and nonreward per se, received the same number of such sessions, but in reverse order. Thus, Phase 1 consisted of sessions of punshment and nonreward trials, and IP treatment was administered in Phase 2. A final IP group (IP-N), receiving IP treatment in Phase 1 and sessions of nonreward trials in Phase 2, was included to control for any effect of interpolated nonreward sessions alone.

\section{METHOD}

\begin{abstract}
Subjects
Eighty-two male rats, purchased from the Holtzman Co. and averaging approximately $360 \mathrm{~g}$ at the end of initial training, were uvatlable. Sixteen were assigned to each group, and the remaining two anunals were included in the IP-PN group. Throughout the experiment, the animals were housed in individual cages, with water ad lib, and were maintained with $1 \mathrm{~h}$ free access to Purina cubes following each session.
\end{abstract}


Table 1

Summary of Treatment During Phase 1 and Phase 2 for Each Group

\begin{tabular}{|c|c|c|c|}
\hline \multicolumn{2}{|r|}{ Groups } & \multicolumn{2}{|c|}{ Treatment } \\
\hline Name & Description & Phase 1 & Phase 2 \\
\hline IP & IP treatment only & Intermittent punishment & Continuous reinforcement \\
\hline IP-PN & $\begin{array}{l}\text { IP treatment followed by punishment } \\
\text { and nonreward sessions }\end{array}$ & Intermittent punishment & $\begin{array}{l}\text { Punishment and non- } \\
\text { reward on each trial }\end{array}$ \\
\hline PN-IP & $\begin{array}{l}\text { IP treatment preceded by punish- } \\
\text { ment and nonreward sessions }\end{array}$ & $\begin{array}{l}\text { Punishment and nonreward } \\
\text { on each trial }\end{array}$ & Intermittent punishment \\
\hline IP-N & $\begin{array}{l}\text { IP treatment followed by nonreward } \\
\text { sessions }\end{array}$ & Intermittent punishment & Nonreward on each trial \\
\hline NIP & No IP treatment & No punishment & Continuous reinforcement \\
\hline
\end{tabular}

\section{Apparatus}

Standard Gerbrands chambers were modified to provide a retractable bar in place of the normal lever. A signal light was positioned $2.5 \mathrm{~cm}$ above the level of the bar directly over the foodcup. Reward consisted of a single 45-mg Noyes pellet, and punishment consisted of a $.35-\mathrm{mA}$ shock of $.06-\mathrm{sec}$ duration throughout the treatment sessions and a shock of $1.5 \mathrm{~mA}$ throughout the testing session. Shock was delivered via a $850-\mathrm{V}$ shock generator with high internal resistance and a load of $100 \mathrm{~K}$. Shock was administered to the animal between the retractable bar and the grid floor of the chamber as soon as the bar contact was closed.

\section{Procedure}

Initial barpress training was carried out in a standard Gerbrands apparatus to a criterion of at least 100 responses within $1 \mathrm{~h}$ for 3 consecutive days ( 9 rats failed to reach this criterion within 7 days of training and were replaced by other animals). Daily sessions of 60 trials each were then given in the experimental chamber. A trial began with the extension of the bar together with the onset of the signal light and ended with bar retraction either when the animal pressed the bar or, if it had not pressed within $20 \mathrm{sec}$, with automatic retraction. The next trial began $10 \mathrm{sec}$ later.

Continuously reinforced barpress training was continued for all animals for 8 daily sessions. Phase 1 of treatment was then begun. For Groups IP, IP-PN, and IP-N, intermittent punishment was administered at this time. Punishment occurred on a randomly selected $25 \%$ of trials. To avoid the possibility of an association forming between punishment and reward, no reward was given on punishment trials. The animals in the NIP group were not punished for responding at this time but received the same number of nonreward trials as animals receiving IP training (to equate the groups for the number of nonreward trials received). For the PN-IP group, every response in this phase was followed by punishment and nonreward. Phase 1 continued for 12 sessions and was followed by a recovery phase of 8 sessions in which all animals were reinforced for each response.

Phase 2 of treatment provided interpolated experience between Phase 1 and testing. I:or IP-PN animals, this phase consisted of blocks of trials on which each response received both punishment and nonreward. Similarly, for IP-N animals, each response was followed by nonreward. The standard IP group continued with CRF throughout this period, as did the NIP group. Finally, the PN-IP group received the same IP treatment that the IP animals had experienced during the first treatment phase. Twelve treatment sessions again were scheduled, and, as before, were followed by 8 sessions of CRF recovery trials. Three animals, one in the IP-N group and two in the NIP group, did not complete treatment. One animal was terminated because of sickness and the remaining two because of an experimental error which resulted in their being punished during a nonpunishment session.
Testing for the IPE consisted of one session during which every response was followed by an intense $(1.5 \mathrm{~mA})$ shock and reward.

\section{RESULTS AND DISCUSSION}

Performance of IP groups during the treatment components of the experiment conformed to that observed in previous experiments (e.g., Banks, 1966). Groups receiving IP showed initial response suppression over the first 3 IP sessions, followed by a gradual recovery over the remaining sessions. By the end of each treatment phase, response strength of IP animals approached that of the baseline period. By contrast, groups receiving blocks of punishment and nonreward trials (IP-PN and PN-IP) showed continual response decrement over the first four sessions, and by the middle of treatment responding was virtually eliminated (a mean of less than one response per session). For animals in the IP.PN group, a mean of 72.3 responses occurred during the 12 treatment sessions, indicating that these animals had considerable opportunity for the extinction of the association between fear and responding. For animals receiving nonreward trials only, responding declined more slowly, but by the last three sessions had dropped to a mean of between 3 and 5 responses per session. During recovery sessions, response times for all groups showed full recovery by the fifth session and performance remained stable during the remaining sessions. Thus, prior to the onset of testing, responding for all groups was rapid (a mean latency of less than $1 \mathrm{sec}$ per trial) and no group differences approached significance.

Performance during testing was assessed in terms of the number of punished responses made by each group. An overall analysis of variance by ranks indicated significant group differences $[\mathrm{H}(4)=12.6 ; \mathrm{p}<.02]$. Individual comparisons of IP groups with the NIP control indicated that the group receiving IP alone (7.12 responses) was more persistent than the NIP group (4.07 responses) $[\mathrm{U}(16 / 14)=55 ; \mathrm{p}<.02]$, as was the IP-N group (6.53 responses) $[\mathrm{U}(15 / 14)=52 ; \mathrm{p}<.05]$ and the PN-IP group (8.88 responses) [U(16/14) $=14.5$; $p<.002]$. The performance of the IP.PN group $(4.83$ 
responses), however, was very similar to that of the control group, and the difference did not approach significance $[U(18 / 14)=100 ; p>.10]$.

The lack of persistence of IP-PN animals indicates that interpolating punishment and nonreward trials between IP training and testing not only reduced the IPE but virtually eliminated it. The fact that animals receiv. ing punishment and nonreward prior to IP training (PN-IP) continued to show a clear IPE, as did animals receiving interpolated nonreward trials (IP-N), indicates that attenuation was due to the positioning of punishment and nonreward after, rather than before, IP training, and that attenuation is not attributable to the interpolation of nonreward trials alone.

These results indicate that conditions which provide for the extinction of an association between fear and an instrumental response are sufficient to reduce and,
In this case at least, 10 elimnate the IPE To thus extent the results conform closely to puedictions from a conditioning model and support the vie: that the IPE can be attributed to an association between fear and the approach response esıablished during IP training.

\section{REFERENCES}

Amsel, A. The role of frustrative nonreward in noncontinuous reward situations. Psychological Bulletin, 1958,55, 102-119. Amsel, A. Frustrative nonreward in partial reinforcement and discrimination learning: Some recent history and a theoretical extension. Psychological Review, 1962, 69, 306-328.

Banks, R. K. Persistence to continuous punishment following intermittent punishment training. Journal of Experimental Psychology, 1966, 71,373-377.

Muller, $N$. E. Learning resistance to pain and fear: Effects of overlearning, exposure, and rewarded exposure in context. Journal of Experimental Psychology, 1960,60, 137-145.

(Received for publication September 2, 1975; accepted September $25,1975$. 